IZA DP No. 8085

FDI impact on Firm Performance in Enlarged Europe:

Evidence from a Meta-Regression Analysis

Randolph Luca Bruno

Maria Cipollina

March 2014 


\title{
FDI Impact on Firm Performance in Enlarged Europe: Evidence from a Meta-Regression Analysis
}

\author{
Randolph Luca Bruno \\ University College London \\ and IZA \\ Maria Cipollina \\ University of Molise \\ Discussion Paper No. 8085 \\ March 2014 \\ IZA \\ P.O. Box 7240 \\ 53072 Bonn \\ Germany \\ Phone: +49-228-3894-0 \\ Fax: +49-228-3894-180 \\ E-mail: iza@iza.org
}

\begin{abstract}
Any opinions expressed here are those of the author(s) and not those of IZA. Research published in this series may include views on policy, but the institute itself takes no institutional policy positions. The IZA research network is committed to the IZA Guiding Principles of Research Integrity.

The Institute for the Study of Labor (IZA) in Bonn is a local and virtual international research center and a place of communication between science, politics and business. IZA is an independent nonprofit organization supported by Deutsche Post Foundation. The center is associated with the University of Bonn and offers a stimulating research environment through its international network, workshops and conferences, data service, project support, research visits and doctoral program. IZA engages in (i) original and internationally competitive research in all fields of labor economics, (ii) development of policy concepts, and (iii) dissemination of research results and concepts to the interested public.
\end{abstract}

IZA Discussion Papers often represent preliminary work and are circulated to encourage discussion. Citation of such a paper should account for its provisional character. A revised version may be available directly from the author. 
IZA Discussion Paper No. 8085

March 2014

\section{ABSTRACT \\ FDI Impact on Firm Performance in Enlarged Europe: Evidence from a Meta-Regression Analysis}

This paper combines, explains and summarizes recent findings from the empirical literature focusing on the FDl's effect on firms' performances by collecting all the relevant firm level quantitative studies to run a regression of regressions focused on Enlarged Europe. The results show that there exists a positive indirect impact of FDI on productivity and ultimately on economic growth in EU, but it is limited in magnitude. Moreover, the effect of FDI on growth is stronger for New EU Members after 2001.

JEL Classification: C81, F23, O52

Keywords: firm performance, Enlarged Europe, meta-regression analysis

Corresponding author:

Randolph Luca Bruno

SSEES, University College London

16 Taviton Street

WC1H 0BW, London

United Kingdom

E-mail: randolph.bruno@ucl.ac.uk

\footnotetext{
*We would like to thank Chris Doucouliagos, Nigel Driffield and Tom Stanley for very useful comments on previous drafts. The usual disclaimer applies.
} 


\section{Introduction}

Historically, foreign direct investment (FDI henceforth) concentrated in advanced economies, which can act both as senders and recipients of FDI. The participation of developing countries in worldwide FDI has risen substantially since the early 1990 s and has become more pronounced after the 2007 financial crisis. UNCTAD figures show that developing countries now attract more than half of global FDI inflows (UNCTAD, 2010, 2012 and 2013). For example in 2011 FDI inflows increased in all major economic groups, developed, developing and transition economies. Developing countries covered 45 per cent of global FDI inflows in 2011, of which East and SouthEast Asia accounted for almost half. On the one hand inflows to Transition Economies of South-East Europe, the Commonwealth of Independent States (CIS) and Georgia accounted for six per cent, (UNCTAD, 2012), but all in all the overall increase in FDI was driven by East, South-East Asia and Latin America. In 2011 FDI outflows to developed countries also grew strongly by reaching $\$ 748$ billion, up 21 per cent from 2010. FDI flows to Europe increased by 19 per cent, mainly owing to large crossborder mergers and acquisitions by foreign multinational corporations (MNCs).

There is a vast literature on the relationship between FDI and economic performance and a quite substantial number of empirical studies on European countries, both for the Old and New Member States (Meyer and Sinani, 2009; Havrenek and Irsova 2010, 2011). Some theoretical models on FDI effects ${ }^{1}$ predict the existence of a favourable impact, direct or indirect, on the host country: in the former case MNCs bring new capital to the economy and therefore enhance the increase of inputs in the production function; in the latter FDI might produce positive 
externalities towards domestic firms, by enhancing firms' productivity and ultimately countrywide economic growth.

This paper will focus on the indirect impact, by recognising the importance of the wider effect of FDI on domestic companies' performance. In fact, in recent years policy makers in many countries have decided to liberalize their policies in order to attract investments from foreign MNCs and therefore to stimulate growth on a wider scale, i.e. for foreign as well as domestic owned companies. As a consequence of this renewed interest towards FDI by scholars, policy makers, practitioners as well as businessmen, there seems to have been a strong effort by governments to lower entry barriers and to offer incentives schemes (tax breaks, subsidies, co-investments, etc.) in order to attract FDI. In other words, governments increasingly recognize the importance of cultivating FDI because they have witnessed how knowledge brought by foreign investors could spill-over to indigenous firms, upgrade the technological capabilities, bolster skills in the local workforce, and consequently increase the overall competitiveness of their economies (World Bank Group, 2010). As a result, new regulatory and industry-targeted measures have been introduced (UNCTAD, 2012).

Despite the theoretical rationale for these positive FDI spillovers ${ }^{2}$ on host country productivity and economic growth, empirical analyses have provided inconclusive or at least inconsistent evidence on the growth/productivity enhancing effect of FDI. In other words different studies show different relationships (positive, negative or not significant). This is evidence that the impact is ambiguous. The lack of robust empirical evidence is probably due to the relevant differences among studies in datasets, sample sizes, models specification, etc.

This paper provides a survey for evaluating and combining the empirical results from a group of studies on the Enlarged Europe and tries to measure the strength of 
the FDI-performance relationship. There is a vast literature on the economic impacts of FDI in EU at the firm, industry and country level.

Given the considerable amount of empirical studies dealing with this subject matter, we will limit our review as follows. On the one hand, we focus on the indirect impact of FDI on host countries and therefore we do not consider all other possible direct impacts on the host country's productivity and growth, i.e. the direct accumulation of more capital in the receiving companies. On the other hand, we take into account studies based on firm-level data only: while rapid growth and high ratios of inward FDI to GDP tend to be witnessed together, causality mechanisms are not easily discernible through aggregate analysis because FDI is often associated with other growth-promoting factors, for example the ratio of investment to GDP and the degree of openness of the economy, among others determinants. ${ }^{3}$ Finally we focus on EU, given the recent surge in FDI, and the political and economic resources devoted by EU governments to remove the still large -explicit and implicit- restrictions to foreign investment (World Bank Group, 2010). We believe that our research sheds some lights on the economic impact of FDI in Europe, which remains one of the main receipts of FDI in the advanced economy world.

Using a meta-regression analysis (MRA) approach this paper provides estimates drawn from random effects models (Borenstein et al., 2009 and 2010) ${ }^{4}$ of the FDI's effect on growth in the EU. The MRA methodology reviews the literature and tries to explain why there is variation in the empirical results reported in the economic studies investigating the same phenomenon. Regression analysis of the existing regression analyses represents a methodology for quantitatively combining all these estimates (commonly referred to as the "effect size"), investigating the sensitivity to variations in the underlying assumptions, identifying and filtering out possible biases, and explaining 
the diversity in the studies' results in terms of heterogeneity of their features (Rose and Stanley, 2005).

The rest of the paper is organized as follows. Section two briefly reviews the empirical literature on FDI's effect. Section three presents key methodological points regarding the MRA approach. Section four introduces the meta-analysis approach and gives some motivations for the so-called "publication bias" analysis. Section five discusses the econometric results. Section six draws some conclusions and policy implications.

\section{Literature Review: effects of FDI on productivity and performance}

FDI can provide direct financing for the acquisition of new plants and equipment, and be an important catalyst of economic restructuring. It can also directly transfer technology to foreign affiliates, as well as indirectly diffuse or "spill over" into local economies. In other words the impact can be direct (on the foreign subsidiary) or indirect (on fully domestic firms). In the latter case, the indirect effect can be horizontal (intra-industry effect) or vertical (inter-industry). Finally, the vertical effect can be divided into forward linkages (downstream domestic customers) and backward linkages (upstream domestic suppliers).

Although FDI is potentially capable of producing all the aforementioned effects it does not follow that it necessarily does, i.e. having the potential will not guarantee the realisation of these externalities (indirect effect). The direct or indirect impacts FDI produces on the host economy might be conditional upon: firstly, the nature of FDI and the reasons why MNCs make such an investment (e.g. market seeking, resource seeking, efficiency seeking, or strategic assets seeking FDI); secondly, the nature and capacity of the host country (absorptive capacity); thirdly, the mode of entry, for example greenfield, takeover or merger and acquisition; finally, the size of entry 
majority/minority shares in domestic firms (Magai, 2012; Bruno, R. and L. M. Falk 2012).

As far as the FDI direct effect is concerned (i.e. when FDI brings capital to the host country) there is sufficient empirical evidence on the positive effect on host countries' firms (Blömstrom and Kokko, 1998; Eichengreen and Kohl, 1998; Holland et al., 2000; Navaretti and Venables, 2004), on the one hand.

On the other hand, the investigation on the existence of an indirect impact (spillovers or externalities) on host countries' firms has been characterized by less conclusive findings, also due to the fact that the results depend on the level of development of a hosting country, whose employment/working conditions, environmental standards, and technology transfer potential towards domestic firms are idiosyncratic. In fact, the indirect effect of FDI on host countries has been largely studied from the perspective of economic growth and development (e.g. in low income countries, Bruno and Campos, 2013), employment/working conditions (labour mobility), the business environment, and technology transfer from foreign to domestic firms. It is widely documented that FDI inflows has the potential to upgrade the technological capabilities, skills, and competitiveness of established domestic firms in the host countries when it generates positive externalities.

The channels through which FDI may spillover from foreign affiliates to other firms in an economy have been analysed in detail in a number of papers (Markusen and Venables, 1999; Kokko, 1992; Javorcik, 2004; Blömstrom and Kokko, 1998). The main channels identified by the literature are imitation/demonstration, movement of workers and competition. Let analyse them in order:

a) Through "imitation" (or eventually through collaboration), domestic firms can learn how to export and reach foreign markets. In other words, their proximity to foreign firms facilitates their learning process; 
b) Movement of labour between companies entails "movement of skills". MNCs have to train the employees in the host country to transfer practices or technology to affiliates (inter-firms mobility and intra-firms training). In fact, a number of empirical studies suggest that the movement of workers within and between firms is indeed one of the most important mechanisms for technology and knowledge spill-overs (Barry et al., 2004 for Ireland; Pesola, 2011 for Finland; and Martins, 2011 for Portugal);

c) Another channel is the "competition effect". It is argued that the entrance of a MNC (owning better technology and managerial practices) will force the host country's firms in similar sectors to use existing technology and resources more efficiently and/or upgrade to more efficient technologies. If they fail, the externality will be negative, i.e. they will not cope with the MNC competition. Indeed, not all of the associated effects are positive: competitive pressure can force domestic firms to exit the industry due to crowding-out or business-stealing effects (Dunning, 1994).

The closer the economy is to the world technology frontier, the more important innovation is with regard to imitation. Keller and Yeaple (2008) show that the complexity of technology makes knowledge costly to transfer, and the problem is exacerbated if the affiliate does not have the absorptive capacity to adapt the new technical knowledge.

In the context of the EU-27, these concepts can be considered particularly relevant for New Member States, which implemented very serious and rapid economic reforms in order to catch up with their neighbouring Old Members.

While FDI flows may go hand-in-hand with economic success, they do not tend to exert an independent effect on growth (Choe, 2003; Carkovic and Levine, 2005; Alfaro et al., 2009). ${ }^{5}$ For example, the macro-/industry-level literature focuses on human capital (Borensztein et al., 1998), on financial markets (Alfaro et al., 2004), on the 
heterogeneity/variety of intermediate goods, on the impact the communication distance between headquarters and production plants and more in general on the absorption capacity (Rodriguez-Clare, 1996). Using a meta-regression analysis, Meyer and Sinani (2009) study the simultaneous effect produced by level of development, institutional frameworks and human capital in the context of countries hosting FDI. Recent studies have explored more specific externality transmission channels: level and rate effect of spill-overs (Liu, 2008), meditating factors and FDI heterogeneity (Smeets, 2008), and multiple simultaneous channels (Javorcik, 2004). Furthermore, recent systematic meta-regression analyses of the updated evidence (Havrenek and Irsova, 2010, 2011; Bruno and Campos, 2013, Bruno and Falk, 2012) further dissect the differential impact of horizontal, backward, and forward spill-overs. Meta-analyses suggest that spill-overs are mainly created through backward linkages to affiliates' suppliers and not forward linkages to their customers. These backward linkages to suppliers suggest that global production networks play an important role in facilitating knowledge transfer.

\section{Empirical Strategy}

With reference to the distinction between the direct and indirect effect of FDI, we consider only papers focusing on the estimation of the indirect impact. The heterogeneity of approaches and specifications of academic papers studying the host country effects of FDI at the firm level is impressive, but it is also possible to consider the "representative" FDI spill-over regression as follows $(z, j$, and $t$ subscripts stand for firm sector and time, respectively):

$$
\ln \left(\text { productivity }_{z j t}\right)=\beta_{j t}^{h} \text { horizontal }_{j t}+\beta_{j t}^{b} \text { backward }_{j t}+\beta_{j t}^{f} \text { forward }_{j t}+\beta_{z j t}^{X} X{ }_{j t}+\varepsilon_{z j t}
$$


where horizontal is usually defined as the ratio of foreign presence in firm z's own sector; backward is the ratio of z's output sold to foreign firms (foreign presence in downstream sectors) and forward is the ratio of z's output purchased from foreign firms (foreign presence in upstream sectors). Using the MRA approach, we evaluate and combine empirical results from different studies and test the null hypothesis that different point estimates, treated as individual observations ( $\left.\beta_{j t}^{f d i}\right)$, are equal to zero when the findings from this entire area of research are combined. Our approach closely follows the MAER-NET reporting guidelines (Stanley et al., 2013).

The first step of the analysis is to build a point estimates database of the FDIgrowth impact relationship. Then, we select papers using the following criteria: (i) written in English, (ii) data based on EU countries, (iii) firm-level data ${ }^{6}$, and (iv) papers on the public domain since 2000 up to 2012. "Data Points" are selected via an extensive search in Google Scholar (http://scholar.google.com) to identify studies in both unpublished and published papers, as well as in research published in peerreviewed journals of the major commercial publishers using the "EconLit", "Web of Science" and "Scopus databases" 7.

When a study provides multiple estimates of the effect under consideration the assumption that multiple observations from the same study are independent draws might be problematic; on the other hand, important information is lost in the grouping process and it is not clear which estimate one should choose as "preferred" for each study (Jeppensen et al., 2002).

According to MRA practise (and wide-spread use in the literature) we collect all estimates and account for both the within-study and between study heterogeneity. We can choose between a Fixed-Effect (FE) and a Random Effect (RE) meta regression model. A FE-MRA model assumes that differences across studies are only due to within-variation. The single, "true" effect is calculated as a weighted average of the 
individual estimates, where the weights are inversely proportional to the square of the standard errors, so that studies with smaller standard errors have greater weight than studies with larger standard errors (Higgins and Thompson, 2002).

The RE-MRA model assumes that the studies are a random sample from the universe of all possible studies (Sutton et al., 2000). In fact, a field of the literature showing high heterogeneity cannot be summarized by the fixed-effects estimate under the assumption that a single "true" effect underlies every study. As a consequence, the FEMRA estimator is inconsistent and the RE-MRA model is more appropriate ${ }^{8}$. The REMRA model assumes that there are real differences between all studies in the magnitude of the effect. Unlike the FE-MRA model, the individual studies are not assumed to be estimating a true single effect-size, rather the true effects in each study are assumed to have been sampled from a distribution of effects. The weights incorporate an estimate of the between-study heterogeneity, $\hat{\tau}^{2}$ (Higgins and Thompson, 2002). ${ }^{9}$

\subsection{Data Sample}

Our final sample includes 46 papers released between 2000 and $2012^{10}$, published in an academic journal, working papers series or unpublished studies, providing 1643 point estimates. The period analysed ranges from 1973 to 2009. The countries analysed in the selected sample are Belgium, Bulgaria, the Czech Republic, Estonia, France, Greece, Hungary, Ireland, Italy, Lithuania, Poland, Portugal, Romania, Spain and the UK. ${ }^{11}$ Most of the observations involve the UK, Ireland (among EU 15 Old Member States), Hungary, Poland and Romania (among New Member States). The studies are mainly organised in panel data. ${ }^{12}$ The results are divided in pure effect and estimates controlling for estimates characteristics. In the former we keep the most rigorous RobuMeta methodology as specification but we do not control for any "moderator" 
variables. In other words, we are unable to explain the heterogeneity of the results, even if we are fully accounting for such heterogeneity ${ }^{13}$. In the latter estimates we insert a battery of FDI-Growth effect, specification and paper specific moderator variables and we use regressions containing country dummies (or alternatively the EU 15 vs. New Member States dummy). In other words, in the regressions with moderator variables we endeavour exploring the sources of such heterogeneity.

\section{Meta-Regression Analysis}

\subsection{Specification}

In our meta-analysis all papers selected contain one or more equations which estimate the indirect effect of FDI on one of the following variables: a measure of firm efficiency (such as TFP), firm output, value-added, or labour productivity. The indirect effect of foreign firms is defined as the impact of foreign ownership on the performance of domestic firms. This effect may be measured as a dummy variable for foreign presence or as the percentage of foreign shares in a domestic firm. This leads to the estimation of the following specification:

$$
r_{i j}=\beta_{0}+e_{i j}+\varepsilon_{i}
$$

where $r_{i j}$ is the partial correlation coefficient (PCC), defined as $\frac{t}{\sqrt{\left(t^{2}+d f\right)}}$ with " $t$ " being the t-statistic of the effect under study, “ $d f$ ” being the degrees of freedom, for the " $j^{i n \text { " }}$ estimation in the " $i^{i t h}$ " paper. $\beta_{0}$ is the underlying average effect, the sampling error is $e_{i j}$ (paper-estimate specific) and the underlying population variance of the RE model is $\varepsilon_{i}$ (paper-specific). The partial correlation coefficient allows direct comparison of studies with different dependent variables (e.g. TFP versus labour productivity). There is an element of heterogeneity in specifications for firm-level databases which 
would make impossible to obtain an underlying aggregate average effect, such as elasticity or semi-elasticity measure. In other words, limiting the reported estimates to a strictly comparable set of specifications would exclude too many studies and as a result, the findings would be based on a very small number of observations.

\subsection{Publication Bias}

Researchers, referees, and editors tend to have a preference for statistically significant results so that a publication bias occurs, greatly affecting the magnitude of the estimated effect. In order to correct publication bias we might use a MRA model that regresses estimated partial correlation coefficients $\left(r_{i, j}\right)$ on their standard errors, se $\left(r_{i, j}\right)$ (Card and Krueger, 1995; Ashenfelter et al. 1999). Meta-regression errors are likely to be heteroscedastic when studies in the literature differ greatly in data sets, sample sizes, independent variables, so the OLS estimates of the MRA coefficients might fail to be unbiased and consistent. A weighted least squares (WLS), obtained dividing the regression equation by the individual estimated standard errors, corrects the MRA for heteroscedasticity and permits to obtain efficient estimates:

$$
\frac{r_{i, j}}{s e_{P C C}}=t_{i, j}=\beta_{0}+\beta_{1} \frac{1}{s e_{P C C}}+\xi_{i, j}
$$

where $t_{i j}$ is the conventional t-value for $r_{i, j}$, the intercept and slope coefficients are reversed and the independent variable becomes the precision, i.e. the inverse of the standard error (Stanley and Jarrell, 2005). Here the precision variable is computed as the inverse of the standard error of the PCC, $\frac{1}{s e_{P C C}}=\sqrt{\left(t^{2}+d f\right)}$.

Equation (3) is the basis for the Funnel Asymmetry Test (FAT-PET): in the absence of publication selection the magnitude of the reported effect will vary randomly around 
the 'true' value, independently of its standard error, therefore $\beta_{0}$ will be zero. In general, when the standard error of the effect of FDI (in the original formulation $\left.r_{i, j}=\beta_{0} s e_{P C C}+\beta_{1}+\varepsilon_{i, j}\right)$ is not significantly different from zero at any conventional level, the publication bias is not a major issue. ${ }^{14}$

Another method to remove or circumvent publication selection is the metasignificance testing (MST). It uses the relationship between a study's standardized effect (its t-value) and its degrees of freedom or sample size $n$ as a means of identifying genuine empirical effect rather than the artefact of publication selection. When there is some genuine overall empirical effect, statistical power will cause the observed magnitude of the standardized test statistic to vary with $n$ (Stanley, 2001).

Finally, Card and Kruger (1995) publication bias test assesses whether the key independent variable, the $\log$ of the square root of the degrees of freedom, has a coefficient of one in absence of publication bias. The results of publication bias will be analysed in the next section

\section{Econometric Results}

\subsection{Econometric Results: Publication Bias}

We explore the publication bias by implementing the FAT-PET, the MST and the Card and Kruger test in Table 1. Let us start with the overall sample (merging Old EU and NMS): results of the FAT-PET in Table 1 show that the intercept $\left(\beta_{o}\right)$ might deviate from zero confirming the presence of publication bias, since the reported effect is not independent of its standard error. However, this result is absent when we analyse the old EU member sample, in other words the publication bias seems to be driven by the estimates on New EU Members. Therefore we are confident that overall the database is mildly affected (by a minority of papers) in terms of publication bias. This is also re-assuring in terms of the choice of the Random Effect model. ${ }^{15}$ 


\section{[Insert Table 1 about here]}

\subsection{Pure Partial Correlation Coefficients regressions}

Examining the entire sample, the average partial correlation coefficient between economic performance (e.g. TFP productivity) and FDI is statistically significant and positive (Table 2). On average, its magnitude is 0.024 (both for the Old EU 15 and the New Members): within the $[-1,1]$ scale this translates in a 2.4 per cent partial correlation. Therefore the correlation results between FDI and productivity for the EU-27 is positive and significant (though small in magnitude), whereas there is no apparent difference between Old EU and New Members. As a first approximation, EU15 countries make a crucial contribution to the positive impact of FDI on productivity as well as New Members, which seems to play a very similar role. In the next section we uncover some interesting caveats to this "first approximation" conclusion that is valid as an average over the $1973-2009$ period. In the next section we discuss the estimates using moderator variables.

[Insert Table 2 about here]

\subsection{Econometric Results controlling for moderator variables}

We now turn to the conditional regressions. Table 3 presents an encompassing set of controls: the type of FDI-Growth relationship, the econometric model, the paper characteristics as well as country dummies. The results are unfolded below.

There is a higher FDI-performance relation when using firm level data (vis-à-vis industry regional or plant data). The OLS estimates (even if controlling for FE) overstates the FDI-performance relation with respect to more sophisticated econometric models. Studies including and higher number of observations (and therefore degrees of freedom) have less strong results. Finally, compared to UK, 
Belgium Estonia Italy and Portugal are exhibiting higher FDI-performance relationship. ${ }^{16}$ Column two does not include countries dummies but just a country group "Old EU” dummy (vis-à-vis New Members) that is insignificant (as already confirmed in the pure effect estimates). By omitting countries dummies the results on moderator variables are only slightly modified and we can confidently state that the columns 2 to 9 are correctly specified.

We distinguish published from unpublished studies. One of the main criticisms of MRA is that because the quality of studies included in the dataset can vary considerably, strong methodological or empirical analyses are lumped together with studies that may have serious methodological or empirical limitations (the "garbage in, garbage out" criticism). It is argued that alternative selection schemes might be considered arbitrary and subjective. The inclusion in meta-databases of both published and unpublished studies is widely viewed as the best way to reduce the so-called "publication bias" (Ashenfelter et al., 1999). Our sample includes 35 published academic journal articles (providing 1212 point estimates) and 11 working papers or unpublished studies (providing 431 point estimates). Since the conventional wisdom is that published and very specific studies tend to include more accurate econometric analyses, we introduce a dummy "published paper". Our results (Table 3) show that the peer-review process does not affect the magnitude of the estimated effect, since the estimated coefficient of the dummy is not statistically significant.

\section{[Insert Table 3 about here]}

Finally in columns 3 to 9 we introduce interacted variables, i.e. the Old EU 15 dummy with the relevant period of analysis $(1995,1996,1997,1998,1999,2000$ or 2001 onwards): the stark result is that the New Members outperform the Old EU-15 (interaction dummy for EU negative and significant) after 2001. This can be interpreted as an encouraging sign for New Members: on the one hand the overall 
effect of FDI on growth is similar to Old EU, but this effect becomes relatively more important in the last decade. This has interesting convergence implications: in light of the last decade catching-up process, New Members States seem to have equipped themselves with a higher FDI impact potential and this might be the fruit of their continuous effort towards a more FDI-friendly environment (World Bank Group, 2010). However is too soon to draw any general conclusions on the improved absorptive capacity of these countries.

\section{Conclusions}

The aim of this paper is to combine, explain and summarize a large number of results on the indirect impact of FDI on economic performance -spillovers- in the Enlarged EU by using a meta-regression analysis approach. This paper discusses some of the more recent findings from the related empirical literature focusing on the Enlarged Europe FDI-growth relationship. Our results show three main findings:

1. the existence of a positive impact of FDI on productivity and ultimately on economic growth in the Enlarged Europe as a whole.

2. the existence of a limited magnitude of this positive relationship; the existence of a mild publication bias, especially in the literature on New EU Members; and inconclusive statistical results on the existence of a genuine effect.

3. the (relative) more important role of New Member States in the contribution towards this effect after 2001.

In view of ours and previous results in the literature, we can argue that policies promoting the inflows of FDI can be a tool for productivity and economic growth, this result being particularly evident for the New Members of EU. From a policy perspective, this paper provides evidence that policy makers' agenda should discuss the 
removal of the still large (explicit and implicit) restrictions to which the access of foreign investors is subject (World Bank Group, 2010).

The European Union is thoroughly investigating the role of foreign investment in "reaping the benefits of globalisation" (European Commission, 2012) for policy purposes. At the same time the quality the available data for empirical estimation is increasing. This seems to be a favourable periods for a renovated effort in the research on FDI and economic growth and this is particularly important given the conditionality of the results (e.g. role of absorptive capacity) and the not always beneficial direction of such externalities (positive spill-overs versus stealing effect negative externalities). More country studies using high quality firm-level data might be extremely useful, but a better synthesis of the existing literature is essential, too. This study falls in the latter approach and we believe this has potentially very important policy relevance. 


\section{References}

Alfaro, L., Chanda, A., Kalemli-Ozcan, S. and S. Sayek (2004), 'FDI and economic growth: the role of local financial markets', Journal of International Economics, 64, 89112.

Alfaro, L., S. Kalemli-Ozcan and S. Sayek (2009), 'FDI, productivity and financial development', The World Economy, 32, 111-135.

Ashenfelter, O., C. Harmon and H. Oosterbeek (1999), 'A Review of Estimates of the Schooling/Earnings Relationship, with Tests for Publication Bias', Labour Economics, 6, $453-70$.

Barry, F., H. Görg, and E. Strobl (2004), 'Foreign direct investment, agglomerations, and demonstration effects: An empirical investigation', Review of World Economics (Weltwirtschaftliches Archiv), Springer, vol. 140(3), 583-600.

Blömstrom, M. and A. Kokko (1998), 'Multinational corporations and spillovers', Journal of Economic Surveys, 12, 247-277.

Borenstein, M., L. V. Hedges, J. P. T.Higgins, and H. R. Rothstein (2010), 'A basic introduction to fixed effect and random effects models for meta-analysis', Research Synthesis Methods, 1, 97-111.

Borenstein, M., L. V. Hedges, J. P. T. Higgins and H. R. Rothstein (2009), Introduction to meta-analysis. West Sussex, UK: John Wiley.

Borensztein, E., J. de Gregorio and J. W. Lee (1998), 'How does foreign direct investment affect economic growth?', Journal of international Economics, 45, 115-135. 
Bruno, R. L. and N. Campos (2013), 'Reexamining the Conditional Effect of Foreign Direct Investment', IZA Discussion Paper no. 7458.

Bruno, R. and L. M. Falk (2012), 'Theories of Foreign Investment and Host Country Effects of FDI', Background Report on FDI flows and impacts on the competitiveness of the EU industry, European Competitiveness Report: Reaping the benefits of globalization, Annual. Luxembourg: Publications Office of the European Union.

Card, D. and A. B. Krueger (1995), 'Time-Series Minimum-Wage Studies: A MetaAnalysis', American Economic Review, 85, 238-43.

Carkovic, M. and R. Levine (2005), 'Does foreign direct investment accelerate economic growth?', University of Minnesota Department of Finance Working Paper314924.

Choe, J. (2003), 'Do foreign direct investment and gross domestic investment promote economic growth?', Review of Development Economics, 7, 44-57.

De Mello, L. R. (1997), 'Foreign Direct Investment in developing countries and growth: a selective survey', Journal of Development Studies, 34(1), 1-34.

Dunning, J. H.(1994) Multinational Enterprises and the Global Economy, Wokingham, UK and Reading, MA: Addison-Wesley.

Eichengreen, B. and R. Kohl (1998), 'The External Sector, the State and Development in Eastern Europe', CEPR Discussion Papers 1904, C.E.P.R. Discussion Papers.

European Commission (2012), European Competitiveness Report: Reaping the benefits of globalization, EU Commission Staff Working Document. 
Havrenek, T. and Z. Irsova (2010), 'Meta-Analysis of Intra-Industry FDI Spillovers: Updated Evidence', Czech Journal of Economics and Finance, 60 (2), 151-174

Havrenek, T. and Z. Irsova (2011), 'Estimating Vertical Spillovers from FDI: Why Results Vary and What the True effect is', Journal of International Economics, 85 (2), 234-244

Higgins, J. P. T. and S. G. Thompson (2002), 'Quantifying Heterogeneity in a MetaAnalysis', Statistics in Medicine, 21, 1539-58.

Holland, D., M. Sass, V. Benaček and M. Gronicki (2000), 'The determinants and impact of FDI in Central and Eastern Europe: a comparison of survey and econometric evidence', Transnational Corporations, 9 (3), 163-213.

Javorcik, B. (2004), 'Does foreign direct investment increase the productivity of domestic firms? In search of spillovers through backward linkages', American Economic Review, 94 (3), 605-627.

Jeppesen, T., J. A. List and H. Folmer (2002), 'Environmental Regulations and New Plant Location Decisions: Evidence from a Meta-Analysis', Journal of Regional Science, 42, pp. 19-49.

Keller, W. and S. R. Yeaple, (2008), 'Global Production and Trade in the Knowledge Economy', NBER Working Papers 14626, National Bureau of Economic Research, Inc.

Kokko, A. (1992), Foreign direct investment, host country characteristics, and spillovers, Doctoral Dissertation, Stockholm School of Economics, Stockholm.

Liu Z. (2008), 'Foreign direct investment and technology spillovers: Theory and evidence', Journal of Development Economics, 85 (1-2), 176-193 
Magai, A. (2012), 'FDI Flows and EU Industrial Competitiveness', Chapter 4 in

European Competitiveness Report 2012: Reaping the benefits of globalization, EU Commission Staff Working Document.

Markusen, J. and A.J. Venables (1999), 'Foreign Direct investment as a catalyst for industrial development', European Economic Review, 43, 335-338.

Martins, P.S. (2011), 'Paying More to Hire the Best? Foreign Firms, Wages, and Worker. Mobility, Economic Inquiry', 49 (2), 349-363.

Meyer, K. and E. Sinani (2009), 'When and Where does foreign direct investment generates positive spillovers? A meta-analysis', Journal of International Business Studies, 40, 1075-1094.

Navaretti, B. and A. Venables (2004), Multinationals and the world economy, Princeton: Princeton University Press.

Pesola, H. (2011), 'Labour Mobility and Returns to Experience in Foreign Firms', The Scandinavian Journal of Economics, 113 (3), 637-664.

Rodriguez-Clare, A. (1996), 'Multinationals, linkages, and economic development', American Economic Review, 86, 851-873.

Rose, A. K. and T. D. Stanley (2005), Meta-Analysis of the Effect of Common Currencies on International Trade', Journal of Economic Surveys, 19, 347-65.

Smeets, R. (2008), 'Collecting the pieces of the FDI knowledge spillovers puzzle', World Bank Research Observer, 23, 107-138. 
Stanley, T.D., (2001), 'Wheat from Chaff: Meta-Analysis as Quantitative Literature Review', Journal of Economic Perspectives, 15, 131-50.

Stanley, T.D. and S. B. Jarrell (2005), 'Meta-Regression Analysis: A Quantitative Method of Literature Surveys', Journal of Economic Surveys, 19, 299-308.

Stanley, T.D., H. Doucouliagos, M. Giles, J. H. Heckemeyer, R. J. Johnston, P. Laroche, J. P. Nelson, M. Paldam, J. Poot, G. Pugh, R. S. Rosenberger and K. Rost (2013), Meta-Analysis of Economic Research Reporting Guidelines Journal of Economic Surveys, 27, 390-394.

Sutton, A. J., K. R. Abrams, D. R. Jones, T. A. Sheldon and F. Song, (2000), Methods for Meta-Analysis in Medical Research, Chichester: JohnWiley.

UNCTAD (2010), World Investment Report 2010: Investing in a Low Carbon Economy, UNCTAD, New York and Geneva.

UNCTAD (2012), World Investment Report 2012: Towards a New Generation of Investment Policies, Geneva: UNCTAD.

UNCTAD (2013), Global Investment Trends Monitor, UNCTAD, New York and Geneva.

World Bank Group (2010), Investing Across Border Report 2010, The World Bank, Washington. 


\section{TABLES}

Table 1 Tests for publication bias

\begin{tabular}{|c|c|c|c|c|c|c|c|c|c|}
\hline \multirow[b]{2}{*}{ Variables } & \multicolumn{3}{|c|}{ Total Sample } & \multicolumn{3}{|c|}{ Old EU 15} & \multicolumn{3}{|c|}{ New Member States } \\
\hline & $F A T-P E T^{u}$ & $M S T^{b}$ & Card-Kruger & $F A T-P E T^{n}$ & $M S T^{b}$ & Card-Kruger & $F A T^{n}$ & $M S T^{b}$ & Card-Kruger $^{b}$ \\
\hline \multirow[t]{2}{*}{$\beta_{i}: 1 /$ se (True) } & 0.003 & & & 0.003 & & & 0.001 & & \\
\hline & $(0.002)$ & & & $(0.003)$ & & & $(0.001)$ & & \\
\hline \multirow[t]{2}{*}{$\beta_{i:} \operatorname{Ln}(n)$} & & $0.237 * * *$ & & & $0.322^{* * *}$ & & & $0.108^{*}$ & \\
\hline & & $(0.073)$ & & & $(0.091)$ & & & $(0.062)$ & \\
\hline \multirow[t]{2}{*}{$\beta_{i}: \operatorname{Ln}($ Square Root DF) } & & & $0.474 * * *$ & & & $0.644^{* * * *}$ & & & $0.215^{*}$ \\
\hline & & & $(0.147)$ & & & $(0.182)$ & & & $(0.123)$ \\
\hline \multirow[t]{2}{*}{$\beta_{0: \text { Intercept }}$} & $0.756^{* *}$ & $-1.648^{* * *}$ & -1.648 & 0.442 & $-2.391 * * *$ & $-2.391^{*} * * *$ & $1.254^{* * *}$ & -0.462 & -0.462 \\
\hline & $(0.351)$ & $(0.650)$ & $(0.65)$ & $(0.440)$ & $(0.817)$ & $(0.817)$ & $(0.592)$ & $(0.538)$ & $(0.538)$ \\
\hline $\mathrm{H}_{0}: \beta_{1}=1$ & & & Rej**** & & & Rej* & & & Rej*** \\
\hline Observations & 1637 & 1041 & 1041 & 961 & 607 & 607 & 976 & 434 & 434 \\
\hline Clusters & 46 & 45 & 45 & 28 & 27 & 27 & 18 & 18 & 18 \\
\hline
\end{tabular}

Standard errors adjusted for studies/clusters are reported in parentheses; $* * * p<0.01, * * \mathrm{p}<0.05, * \mathrm{p}<0.1$

a Dependent variable: t-ratio; ${ }^{b}$ Dependent variable: $\ln \mid$ t-ratio| 
Table 2 EU 27 EU 12 Pure Robust Meta-RE-Analysis

\begin{tabular}{|c|c|c|c|}
\hline RE-MRA Model & Total Sample & Old EU 15 & New Member States \\
\hline$\square$ coefficient & $\begin{array}{l}0.024 * * * \\
(0.008)\end{array}$ & $\begin{array}{l}0.024^{*} \\
(0.012)\end{array}$ & $\begin{array}{l}0.024^{* * *} \\
(0.007)\end{array}$ \\
\hline Observations & 1,643 & 962 & 681 \\
\hline N. Cluster & 46 & 28 & 18 \\
\hline $\mathrm{Tau}^{2}$ & 0.00249 & 0.00265 & 0.000323 \\
\hline
\end{tabular}

Standard errors in parentheses, *** $\mathrm{p}<0.01,{ }^{*} * \mathrm{p}<0.05,{ }^{*} \mathrm{p}<0.1$. 'RobuMeta' command (STATA) clusters the error at the level of the paper. 
Table 3 EU 27 EU 12 Robust-RE-Meta-Analysis with moderator variables

\begin{tabular}{|c|c|c|c|c|c|c|c|c|c|}
\hline & 1 & 2 & 3 & 4 & 5 & 6 & 7 & 8 & 9 \\
\hline & Country Ds & $E U 15 \mathrm{D}$ & $E U 15 D^{*} 1995$ & $E U 15 D^{*} 1996$ & EU $15 D^{*} 1997$ & $E U 15 D^{*} 1998$ & EU $15 D^{*} 1999$ & $E U 15 D^{*} 2000$ & $E U 15 D^{*} 2001$ \\
\hline \multirow[t]{2}{*}{ Vertical FDI } & 0.006 & 0.008 & 0.007 & 0.007 & 0.007 & 0.008 & 0.008 & 0.007 & 0.004 \\
\hline & '(0.013) & $(0.01)$ & $(0.01)$ & $(0.01)$ & $(0.01)$ & $(0.011)$ & $(0.011)$ & $(0.01)$ & $(0.01)$ \\
\hline \multirow[t]{2}{*}{ Firm Level Data } & $0.057 *$ & 0.021 & 0.018 & 0.018 & 0.021 & 0.021 & 0.021 & 0.019 & 0.023 \\
\hline & $(0.032)$ & $(0.025)$ & $(0.024)$ & $(0.024)$ & $(0.025)$ & $(0.025)$ & $(0.025)$ & $(0.026)$ & $(0.027)$ \\
\hline \multirow[t]{2}{*}{ Manufacturing } & 0.017 & 0.008 & 0.011 & 0.011 & 0.008 & 0.007 & 0.007 & 0.008 & -0.005 \\
\hline & $(0.019)$ & $(0.023)$ & $(0.023)$ & $(0.023)$ & $(0.023)$ & $(0.023)$ & $(0.023)$ & $(0.023)$ & $(0.022)$ \\
\hline \multirow[t]{2}{*}{ Non TFP as dependent } & 0.001 & 0.006 & 0.009 & 0.009 & 0.008 & 0.006 & 0.006 & 0.003 & 0.005 \\
\hline & $(0.022)$ & $(0.014)$ & $(0.014)$ & $(0.014)$ & $(0.014)$ & $(0.016)$ & $(0.016)$ & $(0.015)$ & $(0.013)$ \\
\hline \multirow[t]{2}{*}{ Interacted FDI } & 0.005 & -0.011 & -0.012 & -0.012 & -0.012 & -0.011 & -0.011 & -0.011 & -0.014 \\
\hline & $(0.018)$ & $(0.01)$ & $(0.01)$ & $(0.01)$ & $(0.01)$ & $(0.011)$ & $(0.011)$ & $(0.01)$ & $(0.011)$ \\
\hline \multirow[t]{2}{*}{ Not OLS estimator } & $-0.044^{* *}$ & $-0.044^{*} *$ & $-0.048^{*} *$ & $-0.048 * *$ & $-0.046^{* *}$ & $-0.044^{*} *$ & $-0.044^{*} *$ & $-0.044^{*} *$ & $-0.045^{* *}$ \\
\hline & $(0.019)$ & $(0.02)$ & $(0.02)$ & $(0.02)$ & $(0.02)$ & $(0.021)$ & $(0.021)$ & $(0.02)$ & $(0.02)$ \\
\hline \multirow[t]{2}{*}{ Data Length in Years } & -0.003 & $-0.006^{* *}$ & -0.005 & -0.005 & $-0.006^{*}$ & $-0.006^{* *}$ & $-0.006^{* *}$ & $-0.007 * *$ & $-0.007^{* *}$ \\
\hline & $(0.005)$ & $(0.002)$ & $(0.003)$ & $(0.003)$ & $(0.003)$ & $(0.003)$ & $(0.003)$ & $(0.003)$ & $(0.003)$ \\
\hline 1995-2000 end Year & -0.073 & $-0.080^{* *}$ & $-0.082^{* *}$ & $-0.082^{*} *$ & $-0.080^{* *}$ & $-0.080 * *$ & $-0.080^{* *}$ & $-0.081 * *$ & $-0.076^{* *}$ \\
\hline
\end{tabular}




\begin{tabular}{|c|c|c|c|c|c|c|c|c|c|}
\hline & $(0.049)$ & $(0.036)$ & $(0.036)$ & $(0.036)$ & $(0.036)$ & $(0.037)$ & $(0.037)$ & $(0.036)$ & $(0.035)$ \\
\hline \multirow[t]{2}{*}{ 2000-2005 end Year } & -0.073 & $-0.075^{* *}$ & $-0.091 * * *$ & $-0.091 * * * *$ & $-0.082^{* *}$ & $-0.075^{*} *$ & $-0.075^{* *}$ & $-0.074 * *$ & $-0.071 * *$ \\
\hline & $(0.047)$ & $(0.034)$ & $(0.032)$ & $(0.032)$ & $(0.032)$ & $(0.034)$ & $(0.034)$ & $(0.033)$ & $(0.034)$ \\
\hline \multirow[t]{2}{*}{ after 2005 end Year } & -0.083 & -0.046 & $-0.065^{*}$ & $-0.065^{*}$ & -0.054 & -0.045 & -0.045 & -0.018 & -0.015 \\
\hline & $(0.051)$ & $(0.037)$ & $(0.037)$ & $(0.037)$ & $(0.034)$ & $(0.033)$ & $(0.033)$ & $(0.024)$ & $(0.028)$ \\
\hline \multirow[t]{2}{*}{ Published Paper } & 0.000 & 0.001 & 0.003 & 0.003 & 0.003 & 0 & 0 & -0.004 & 0.001 \\
\hline & $(0.016)$ & $(0.014)$ & $(0.013)$ & $(0.013)$ & $(0.014)$ & $(0.017)$ & $(0.017)$ & $(0.015)$ & $(0.013)$ \\
\hline \multirow[t]{2}{*}{ Log Square Root DF } & $-0.027 * *$ & $-0.020^{* * *}$ & $-0.021 * *$ & -0.021 *** & $-0.020^{* *} *$ & $-0.019 * *$ & $-0.019^{* * *}$ & $-0.020 * *$ & $-0.021 * *$ \\
\hline & $(0.011)$ & $(0.009)$ & $(0.009)$ & $(0.009)$ & $(0.009)$ & (0.009) & $(0.009)$ & $(0.009)$ & $(0.008)$ \\
\hline \multirow[t]{2}{*}{ EU 15 Dummy } & & -0.004 & -0.022 & -0.022 & -0.011 & -0.003 & -0.003 & -0.001 & 0 \\
\hline & & $(0.012)$ & $(0.016)$ & $(0.016)$ & $(0.016)$ & $(0.012)$ & $(0.012)$ & $(0.012)$ & $(0.012)$ \\
\hline \multirow[t]{2}{*}{ EU 15 Dummy*1995 } & & & 0.037 & & & & & & \\
\hline & & & $(0.024)$ & & & & & & \\
\hline \multirow[t]{2}{*}{ EU 15 Dummy*1996 } & & & & 0.037 & & & & & \\
\hline & & & & $(0.024)$ & & & & & \\
\hline \multirow[t]{2}{*}{ EU 15 Dummy*1997 } & & & & & 0.016 & & & & \\
\hline & & & & & $(0.026)$ & & & & \\
\hline \multirow[t]{2}{*}{ EU 15 Dummy* 1998} & & & & & & -0.002 & & & \\
\hline & & & & & & $(0.04)$ & & & \\
\hline
\end{tabular}


EU 15 Dummy*2000

$\begin{array}{rr}\text { Yes*** } & \text { No } \\ 1,643 & 1,643 \\ 46 & 46\end{array}$

Observations

N. Cluster

Standard errors in parentheses, ${ }^{* * *} \mathrm{p}<0.01,{ }^{*} * \mathrm{p}<0.05,{ }^{*} \mathrm{p}<0.1$. 'RobuMeta' command (STATA) clusters the error at the level of the paper.

The Omitted categories are UK(1st column), Horizontal FDI, Not firm Level Data, Not Manufacturing data, TFP as dependent variable, pure effect of FDI (i.e. not interacted), OLS (and panel FE) estimator, database stopping before 1995 (end year), unpublished paper, New EU Members (for the EU 15 dummy in columns 2 to 9). 


\section{NOTES}

\footnotetext{
${ }^{1}$ These are mainly focused on advanced economies though (see Bruno and Falk 2012).

${ }^{2}$ For a comprehensive survey of literature see De Mello (1997).

${ }^{3}$ This leads to omitted variables biases.

${ }^{4}$ RobuMeta command in STATA.
}

${ }^{5}$ Using a panel VAR model to explore the interaction between FDI and economic growth in 80 countries in the period 1971-1995, Choe (2003) finds evidence that FDI Granger cause economic growth, but the opposite is also true and it is economically and statistically stronger. Carkovic and Levine (2005) use GMM to study a large sample of countries between 1960 and 1995, and find no robust causal effect between foreign investment inflows and economic growth. Similarly, Alfaro et al. (2009) find no significant evidence of a positive impact of FDI on growth, except for some financially developed countries.

${ }^{6}$ We exclude papers at the aggregate cross-country level.

${ }^{7}$ A complete list of the full sample of papers, detailed information on estimates and a richer set of general information on each and every paper are available from the authors.

${ }^{8}$ We use the RobuMeta command for this purpose. We are aware that the presence of Publication Bias (PB) would make the Random effects is more biased than Fixed effects, but we think that we can still work with former due to the relatively mild assessment of PB in our sample, see section 4.2.

${ }^{9}$ Each effect size differs from the underlying population mean, $\mu$, due to both sampling error $e$ and the underlying population variance $\varepsilon$ : effect $t_{i}=\mu+e_{i}+\varepsilon_{i}$; where $e_{i} \sim N\left(0, v_{i}^{2}\right)$ and $\varepsilon_{i} \sim N\left(0, \tau_{i}^{2}\right)$.

${ }^{10}$ This has to be considered when our search has been brought to an end. Other papers might have been published more recently.

${ }^{11}$ Three articles included in the MRA cover a group of countries instead a single nation, namely Central and Eastern Europe; the EU-15; Bulgaria, Poland, and Romania. They still perform a firm-level econometric investigation and have therefore been included in the MRA. 
12 This statistical property is quite important in guaranteeing less biased estimates. Cross-section estimates would be upwardly biased and would be less suitable for a MRA.

${ }^{13}$ See RobuMeta help on STATA 12.

${ }^{14}$ In such a case, the standard error can be omitted from the regression.

${ }^{15}$ On a different note the FAT-PET does not report a genuine effect of FDI on economic performance. The MST test, on the other hand, provides evidence of a genuine empirical effect of FDI on economic performance, since the $\beta_{1}$ estimate is statistically significant for the total sample, as well as for the Old and New EU members. The MST is no more used a reliable test for detecting genuine effects, though and we rely on the FAT-PET instead. Finally, the Card-Kruger publication bias test leads to the rejection of the null hypothesis that $\beta_{1}=1$ : the positive relationship between t-ratios and degrees of freedom signals a mild publication bias.

${ }^{16}$ For column 1, countries dummies are available upon request. 